\title{
Phase Transitions in Some Phase Changing Organic Materials Studied by Nuclear Magnetic Resonance Relaxometry
}

\author{
Kashaev R.S.-H. , A.G.N.Masiab \\ Kazan State Power Engineering University,420107, Kazan, Esperanto \\ *Corresponding Author: kashaev2007@yandex.ru
}

Copyright $@ 2013$ Horizon Research Publishing All rights reserved.

\begin{abstract}
Using nuclear magnetic resonance relaxometry and calorimetry methods were studied phase transitions in isoparaffin $i-\mathrm{C}_{22} \mathrm{H}_{46}$ and paraffin added bitumen. They can be used as a phase-changing materials (PCM) and so as heat accumulating/emitting thermal electric energy storage. For studies of phase transitions time and temperature dependences on protons was used relaxometer NMR 09/PC on resonance frequency $v_{\mathrm{o}}=9,2 \mathrm{M} ц$. Were received data on structure-dynamical NMR-parameters, determining properties of studied organic materials. Was discovered prolonged complex form of phase transition through many stage crystallization process, which does not satisfy the criteria of phase transitions of I or II order.
\end{abstract}

Keywords Nuclear Magnetic Resonance, Phase Transitions, Phase Transition Materials

\section{Introduction}

Investigations on direct electric energy production using phase transition (PT) of phase-changing materials (PCM) is of great technology relevance. Solution of the problem gives an opportunity for use of temperature changes during 24 hours, especially in the regions with sharp continental climate. Such materials are named thermal energy storage (TES) systems, widely used in air conditioning systems for its benefits on energy conservation [1-3]. Phase transitions can be also used for power generation - transformation of heat of fusion/crystallization in electric current power as a most convenient form of energy. For this purpose can be used the thermoelectric Seebek effect of electricity production using temperature over fall during the process of PT at heating and cooling. [4]. But phase transitions are not studied completely and is a complicated phenomena. Noble laureate V.L.Ginsburg put it on the seventh place among physic problems, that are needed to be solved.

\section{Samples, Apparatus and Measurements Methods}

As a samples were isoparaffin $i-\mathrm{C}_{22} \mathrm{H}_{46}$ (docozan) with average number of $\mathrm{C}$ atoms in chain, with density $\rho=774,9$ $\mathrm{kg} / \mathrm{m}^{3}$, molecular weight $M=310.6$, melting temperature $T_{\mathrm{m}}$ $=44^{\circ} \mathrm{C}$, temperature and heat of allotroph transformation $T_{\mathrm{A}}$ $=43^{\circ} \mathrm{C}$, change of enthalpy $\Delta H_{\mathrm{A}}=6,74 \mathrm{kcal} / \mathrm{mol}$, temperature of crystallization $T_{\mathrm{cr}}=30,4^{\circ} \mathrm{C}$ [5] with heat of $\Delta H_{\mathrm{C}}=11,7$ $\mathrm{kcal} / \mathrm{mol}$. Another more complex sample was bitumen. By infrared analysis data [6] paraffin relative content in bitumen is 3,9-9,5\% from all paraffin content and $\mathrm{C}=22$ is the mean number of $\mathrm{C}=12-34$ of paraffin's. So $i-\mathrm{C}_{22} \mathrm{H}_{46}$ can be considered as the average paraffin in bitumen. Bitumen have the following properties: paraffin $-12,4 \%$, density $\rho=1.06$ $\mathrm{g} / \mathrm{cm}^{3}$, oils (paraffins and aromatics) - 38.18\%, resins $36 \%$, asphaltenes $-25.75 \%$, temperature of softening $T_{\mathrm{S}}=$ $48.5^{\circ} \mathrm{C}$. For compare bitumen BND $90 / 130$ by ASTM D $1754-83$ testing has paraffin-naphthenes $-19.0 \%$, aromatics $-27.2 \%$, resins $-32.7 \%$ asphaltenes -21.1 [5.]. It should be mentioned, that $T_{\mathrm{S}}$ is the temperature of the beginning of plastic deformation and it does not correspond to temperature of molecular free motion at high temperature approximation.

For measurements of NMR-relaxation structure-dynamical parameters (SDP): spin-lattice $T_{1 \mathrm{i}}$, spin-spin $T_{2 \mathrm{i}}$ relaxation times the NMR relaxometer NMR-09/PC was used on resonance frequency $v_{0}=9,2 \mathrm{MHz}$ [7]. Temperature of measurements was changed and maintained with accuracy $\pm 0,2^{\circ}$ by thermo stabilization device, described in our patent [8].

Spin-lattice $T_{1 \mathrm{i}}$ relaxation times were determined using spin-echo recovery sequence $90-\tau-90^{\circ}-\tau_{0}-180^{\circ}$ of Hahn [9]. Measurement parameters were: pulses repetition delay time $T=9 \mathrm{~s}$, number of pulses steps $N=100$ with a step $\tau=3$ $\mathrm{ms}, \tau_{0^{-}} 200 \mu \mathrm{s}$, number of accumulations $n=3$. For spin-spin $T_{2 \mathrm{i}}$ relaxation times measurements $90^{\circ}-\tau-\left(180^{\circ}-2 \tau-\right)_{\mathrm{N}}$ sequence of Carr-Purcell-Meiboom-Gill [10] was used, eliminating influence of self-diffusion and protons exchange. 
$T_{2 \mathrm{i}}$ were measured with delay time $T=9 \mathrm{~s}$, number of $180^{\circ}$ pulses $N=900$, interval $\tau$ between $180^{\circ}$ pulses $-200 \mu \mathrm{s}$, number of accumulations $n=10$.

Main instrumental error was: $\gamma_{0}= \pm 1,44 \%$. Experimental error of relaxation times measurements: for $\pm 3 \div 4 \%$ and \pm $2 \%$ for NMR-signal amplitudes recurrence, depending from accumulations number $n$, so error could be reduced $(n)^{1 / 2}$ times using $n$ accumulations. Sample probe head has $\varnothing 30$ $\mathrm{mm}$, so the sample volume $V$ for probe filling height $h=35$ mm was $V=25 \mathrm{~cm}^{3}$, large enough for sample representation. Coefficient of sensibility $K=v^{2} V\left[\mathrm{MHz}^{2} \mathrm{~cm}^{3}\right]$ in used NMR-relaxometer is $K=4150 \mathrm{MHz}^{2} \mathrm{~cm}^{3}$, that is close to $K=$ 1600-6400 $\mathrm{MHz}^{2} \mathrm{~cm}^{3}$ of "Minispec pc120" (Bruker, Germany). Besides, relaxometer has a He-Ne laser devise for irradiation of the samples at wave lengths $\lambda=532$ and 633 $\mathrm{nm}$. It was described in [11].

Spin-echo amplitudes $A_{\mathrm{e}}$ envelopes dependences in Hahn and CPMG-methods after the amplitude detection had forms, which can be described by equations:

$$
\begin{gathered}
A_{e}=1-\sum A_{1 \mathrm{i}} \exp \left(-t / T_{1 \mathrm{i}}\right) \\
i=A, B, C \\
A_{\mathrm{e}}=\sum A_{2 \mathrm{i}} \exp \left(-t / T_{2 \mathrm{i}}\right) \\
\quad i=A, B, C
\end{gathered}
$$

where $\mathrm{A} 1 \mathrm{i}$ and $\mathrm{A} 2 \mathrm{i}$ (in arbitrary units) correspond to initial amplitudes of $\mathrm{A}, \mathrm{B}$ for $\mathrm{i}-\mathrm{C} 22 \mathrm{H} 46$ and $\mathrm{A}, \mathrm{B}$ and $\mathrm{C}$ protons for bitumen, participating in three types of molecular motions which determine relaxation times $\mathrm{T} 1 \mathrm{i}$ and $\mathrm{T} 2 \mathrm{i}$. From measured spin-echo amplitudes data logarithms are taken, and the curves were decomposed on three linear components, corresponding to $\mathrm{T} 1 \mathrm{i}$ and $\mathrm{T} 2 \mathrm{i}$, and which are attributed to three proton phases A, B and C. Terminology "proton phase" is not identical to aggregate state, but corresponds to relaxation, caused by dipole-dipole interactions in paraffin's molecular fragments ( $\mathrm{A}$ in the end - $\mathrm{CH} 2-\mathrm{CH} 3$ - groups and B - in ...-CH2-CH2-...parts with different degrees of molecular motion restrictions.

$$
\text { ... } \mathrm{CH}_{2}-\mathrm{CH}_{2}-\mathrm{CH}_{2}-\ldots
$$

Relaxation function can be approximated by the sum of exponents if $T_{1,2 \mathrm{i}}$ difference is large enough [14]. Tyat is so, and for relaxation times determination we used graph-analytical method of spin-echo envelopes dependences decomposition, described earlier in [7].

Molecular motion activation energies $E_{a}$ of the linear parts of $T_{1}$ and $T_{2}$ were defined from reverse temperatures $\left(10^{3} / T\right)$ temperature dependences using program Advanced Grafer. For Arrenius form of correlation times dependence $\tau_{\mathrm{c}}=$ $\tau_{\mathrm{o}} \exp \left(E_{\mathrm{a}} / R T\right)$ (where $\tau_{\mathrm{o}}$ period of atom oscillation, $R=8,314$ $\mathrm{J} / \mathrm{mol}$ - universal gas constant) at high temperature approximation $2 \pi \nu_{\mathrm{o}} \tau_{\mathrm{c}}<<1$, relaxation times are equal $T_{1}=$ $T_{2}$, and for intramolecular contribution in relaxation the activation energy $E_{\mathrm{a}}$ can be determined from $T_{1,2}{ }^{(2)}$ и $T_{1,2}{ }^{(1)}$ for temperatures $T^{(1)}$ and $T^{(2)}$ using [13]:

$$
E_{\mathrm{A}}(\text { Дж/моль })=19,13 \lg \left(T_{1,2}{ }^{(2)} / T_{1,2}{ }^{(1)}\right)\left[T^{(1)} T^{(2)} /\left(T^{(2)}-T^{(1)}\right)\right],
$$

Error of $E_{\mathrm{a}}$ determination is the sum of instrumental. relaxation times and temperature errors:

$$
\Delta E_{\mathrm{a}} / E_{\mathrm{a}}=\Delta \lg T_{1,2} / \lg T_{1,2}+\Delta T^{(1)} / T^{(1)},
$$

and equal to $\gamma_{\mathrm{E}}= \pm(1,4+3,5+0,4) \approx \pm 5 \%$.

Analysis techniques used to study phase transitions are conventional calorimetric, differential scanning calorimetric (DSC) and differential thermal analysis (DTA). As it is mentioned by Gibbs [3], there is considerable uncertainty about the property values provided by manufacturers. Yinping [3] reviewed conventional calorimetric methods and pointed out their limitations such as: a) too small quantities of sample can be analyzed (1-10 mg), but some properties depend on sampler volume; b) phase changes cannot be visually observed. According to [14] error of DTA reach \pm $3 \%$ at measurement range ends. Following [3] recommendations calorimetric we elaborated design, which combine common and differential calorimetric and additionally determine Seebeck thermoelectric tension $U(\mathrm{mV})$ and current $I(\mathrm{mcA})$ of endo/xothermic effects. Small was used. One solder of thermo element TEMO-7 (40x60 $\mathrm{mm}$ ) is connected with heat conducting plate immersed in paraffin or bitumen. Another solder is connected with radiator freeze by cooler or ice. Usually point of melting is determined during 15 minutes. We controlled cooling process during 100-180 minutes in the sample of volume $\approx$ $100 \mathrm{ml}$. Temperatures in sample and water were measured by thermo resistors of the II class of precision $(\Delta t= \pm(0,30+$ $\left.3,5 \cdot 10^{-3} t\right)$ in the temperature range $-50{ }^{\circ} \mathrm{C} \leq T \leq+180{ }^{\circ} \mathrm{C}$ with resistivity $R=50 \mathrm{Ohm}$, maintained with Winston (bridge) power. Resistivity is determined from equation $R_{\mathrm{t}}=$ $R_{\mathrm{o}}(1+\alpha T)$, where $\alpha=4,26 \cdot 10^{-3} \mathrm{~K}^{-1}$. Temperature measurement error was $\pm 0.1 \%$.

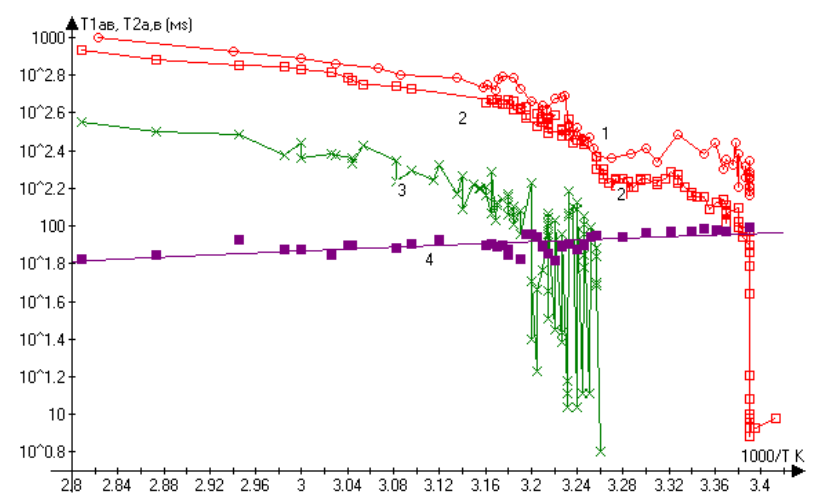

Figure 1. Temperature dependence of spin-lattice $T_{1 \mathrm{~A}}$ (curve 1), spin-spin $T_{2 \mathrm{~A}, \mathrm{~B}}$ (curves 2,3 ) relaxation times from $10^{3} / \mathrm{T} \mathrm{K}$ and $P_{2 \mathrm{~A}}$ proton population (line 4) at cooling of $i-\mathrm{C}_{22} \mathrm{H}_{46}$.

\section{Experimental Results}


Experimental results of NMRR-analysis of $i-\mathrm{C}_{22} \mathrm{H}_{46}$ are presented at the figs. 1 and 2 as the temperature (fig. 1) and time (fig. 2) dependences of spin-lattice $T_{1 \mathrm{~A}}(\mathrm{~ms})$ and spin-spin $T_{2 \mathrm{~A}, \mathrm{~B}}(\mathrm{~ms})$ relaxation times from inverse temperature $10^{3} / T \mathrm{~K}$ and time $t(\mathrm{~min})$ of cooling.

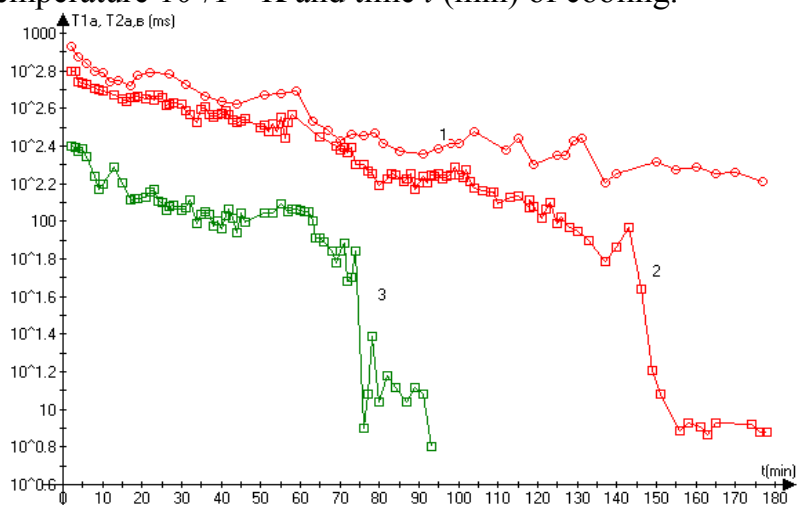

Figure 2. Time dependences of spin-lattice $T_{1 \mathrm{~A}}$ (curve 1), spin-spin $T_{2 \mathrm{~A}, \mathrm{~B}}$ (curves 2,3) relaxation times from time $t$ of $i-\mathrm{C}_{22} \mathrm{H}_{46}$ cooling

Results of calorimetric analysis as dependence of temperature $T_{\mathrm{D}}\left({ }^{\circ} \mathrm{C}\right)$ of $i-\mathrm{C}_{22} \mathrm{H}_{46}$, water (it has no phase transitions in this temperature range) and voltage $U(\mathrm{mV})$ of thermo element (thermoelectric force) from time $t$ of cooling are presented at fig. 3 .

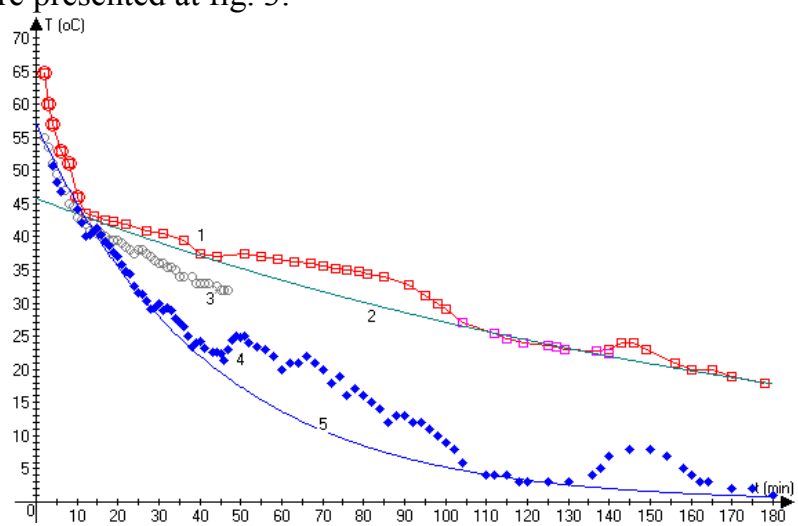

Figure 3. Time dependence of temperature $T_{\mathrm{D}} \quad\left({ }^{\circ} \mathrm{C}\right)$ of $\mathrm{i}-\mathrm{C}_{22} \mathrm{H}_{46}$ (curve 1), water (curve 3), voltage $U(\mathrm{mV})$ (curve 4$)$ at cooling. Curves 2 and 5 - base lines for $T_{\mathrm{D}} \quad\left({ }^{\circ} \mathrm{C}\right)$ and $U(\mathrm{mV})$.

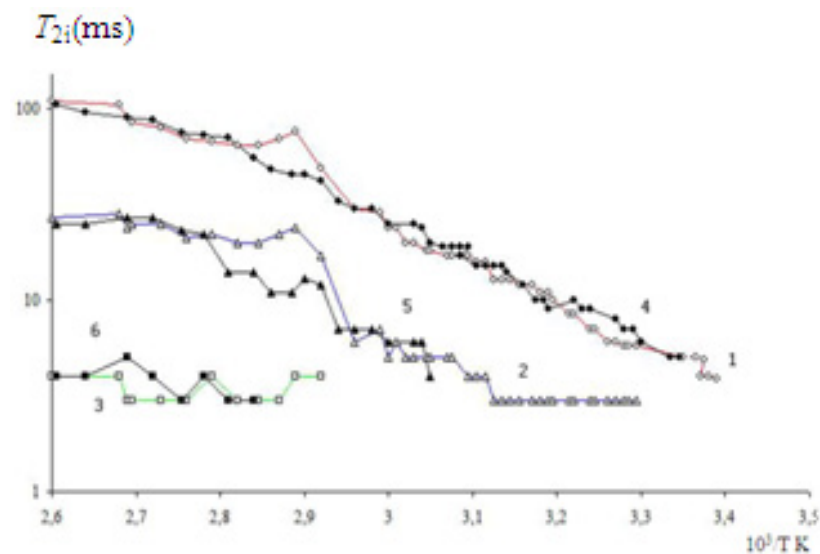

Figure 4. Temperature dependences of spin-spin relaxation times $T_{2 \mathrm{~A}}(\mathrm{~ms})$ $T_{2 \mathrm{~B}}$ and $T_{2 \mathrm{C}}$ (curves 1-3) before and after laser irradiation at $\lambda=0,63$ мкм (curves 4-6) in bitumen at cooling.
For bitumen at fig. 4 temperature dependences of spin-spin relaxation times $T_{2 \mathrm{~A}}, T_{2 \mathrm{~B}}$ and $T_{2 \mathrm{C}}$ from inverse temperature $10^{3} / \mathrm{T} \mathrm{K}$. Curves 1 and 2 represent relaxation time dependences before irradiation; curves 4,5 - after laser irradiation at $\lambda=0,63$ of bitumen. At fig.5. - time dependences of $T_{2 \mathrm{~A}}, T_{2 \mathrm{~B}}$ and $T_{2 \mathrm{C}}$ at cooling. At fig.6 dependence of bitumen temperature $T_{\mathrm{B}}\left({ }^{\circ} \mathrm{C}\right)$ from time $t$. $T_{2 \mathrm{i}}(\mathrm{ms})$

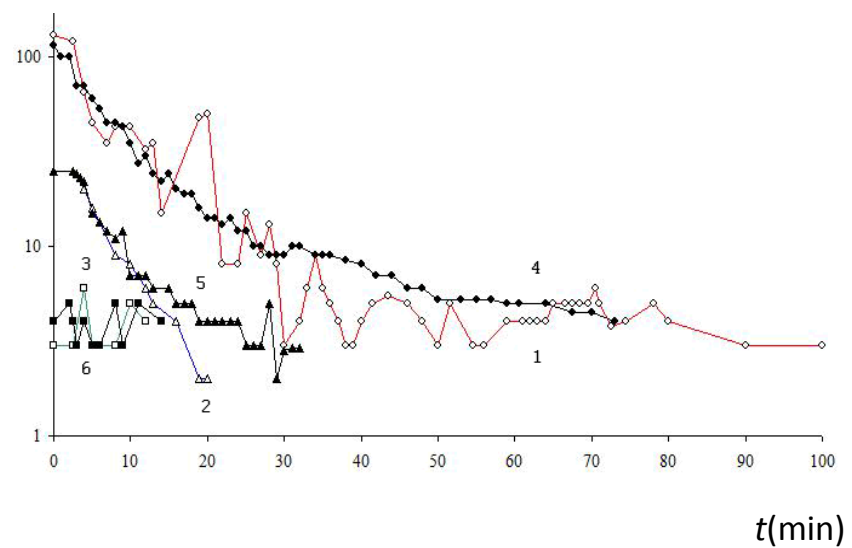

Figure 5. Time dependences of spin-spin relaxation times $T_{2 \mathrm{~A}}(\mathrm{~ms}) T_{2 \mathrm{~B}}$ and $T_{2 \mathrm{C}}$ (curves 1-3) and after laser irradiation at $\lambda=0,63 \mu \mathrm{m}$ (curves 4-6) in bitumen at cooling.

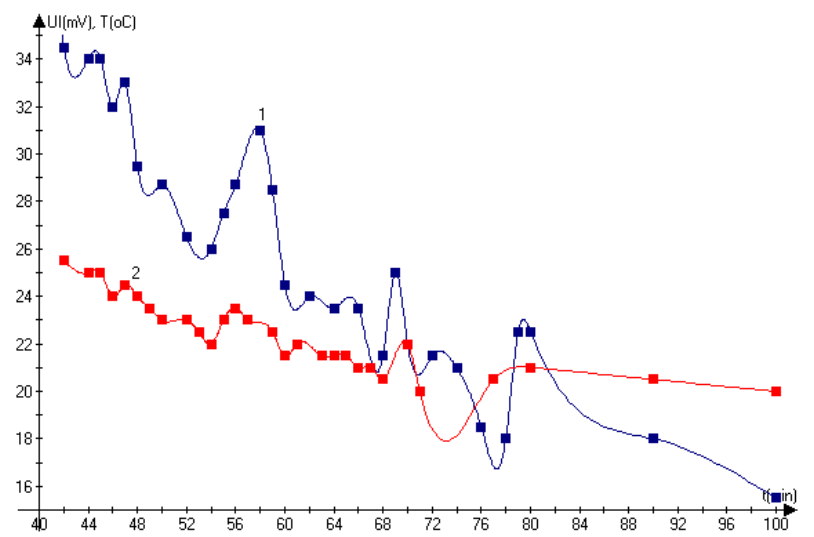

Figure 6. Time dependence of thermo element current $U(\mathrm{mV})$ (curve 1) and temperature (curve 2 ) at cooling of bitumen.

\section{Discussion}

Paraffin $i-\mathrm{C}_{22} \mathrm{H}_{46}$

Before interpretation of relaxation temperature dependences at fig. 1 it must be considered, that relaxation rate $\left(T_{1,2}\right)^{-1}$ have two types of contributions:

- intramolecular $\left(T_{1,2}\right)^{-1}$ int, which characterize relaxation from reorientations of $\mathrm{CH}_{3}$ groups and cis-trans configuration motion of ...- $-\mathrm{CH}_{2}-\mathrm{CH}_{2}-\mathrm{CH}_{2} \ldots$ chains:

$$
\left(T_{1,2}\right)_{\text {int }}{ }^{-1}=3 \gamma^{4} h^{2} \tau_{\mathrm{R}} / 8 \pi^{2} R_{\mathrm{ij}}{ }^{6}
$$

giving low $T_{1,2}$ at short $R_{\mathrm{ij}}$ in crystal form;

- intermolecular $\left(T_{1,2}\right)^{-1}$ tr from translational forms of motions in melt of $i-\mathrm{C}_{22} \mathrm{H}_{46}$ [13]: 


$$
\left(T_{1,2}\right)_{\mathrm{tr}}^{-1}=\pi \gamma^{4} h^{2} N_{\mathrm{I}} \tau_{\mathrm{D}}\left(1+2 a_{\mathrm{o}} / 5 D \tau_{\mathrm{D}}\right) / 4 a_{\mathrm{o}}{ }^{3}
$$

where $\gamma / 2 \pi=4256 /$ sec gauss - gyromagnetic ratio for protons, $h=6,626 \cdot 10^{-34} \mathrm{~J} / \mathrm{s}-$ Plank constant, $N_{\mathrm{I}}=6,75 \cdot 10^{28}$ $\mathrm{m}^{-3}$ - number of spins in $\mathrm{cm}^{3}, a_{\mathrm{o}}$ - average molecular diameter, $R_{\mathrm{ij}}-$ average distance between protons, $\tau_{\mathrm{R}}$ and $\tau_{\mathrm{D}}-$ correlation times of rotational and translational motions $\left(\tau_{\mathrm{D}}\right.$ $\left.=a_{\mathrm{o}} / 12 D\right), D$ - self diffusion coefficient of molecules.

In colloid systems $\left(T_{2 \mathrm{i}}\right)_{\text {int }}{ }^{-1}$ is sufficiently greater, than $\left(T_{2 \mathrm{i}}\right)_{\mathrm{tr}}{ }^{-1}$, for instance even for compact benzol molecules $\left(T_{2 \mathrm{i}}\right)_{\mathrm{tr}}{ }^{-1}$ is equal $4,5 \%$ from the relaxation rate [13]. That's why in our high-temperature approach $2 \pi v \tau_{\mathrm{R}}<<1$ of paraffin melt we used eq.(5) for relaxation times calculations. Then, usually $\tau_{\mathrm{R}}$ have Arrenius form $\tau_{\mathrm{R}}=\tau_{\mathrm{o}} \exp \left(E_{\mathrm{A}} / R T\right)$, and so eq(5) can be rewritten as:

$$
T_{1,2 \mathrm{~B}}{ }^{-1}=\left(3 \gamma^{4} h^{2} / 4 \pi^{2} R_{\mathrm{ij}}{ }^{6}\right) \tau_{\mathrm{o}} \exp \left(E_{\mathrm{A}} / R T\right)
$$

And inter-proton distances $R_{\mathrm{ij}}$ can be calculated using it.

At temperature dependences of relaxation times $T_{2 \mathrm{i}}$ for isoparaffin at fig. 1 several temperature ranges with different behavior of $T_{2 \mathrm{i}}$ can be elucidated. They are the following:

i) Range $10^{3} / \mathrm{T}=2,8-3,16\left(84-43^{\circ} \mathrm{C}\right)$ of relatively monotone decrease of $T_{2 \mathrm{~A}}$ and $T_{2 \mathrm{~B}}$ with the activation energies $E_{\mathrm{A} 2 \mathrm{~A}}=12.35 \mathrm{~kJ} / \mathrm{mol}, E_{\mathrm{A} 2 \mathrm{~B}}=13.6 \mathrm{~kJ} / \mathrm{mol}$ (left part of the curves 1 and 2) of the paraffin melt. The end of this range is at temperature $44^{\circ} \mathrm{C}$ of phase transition and at $43^{\circ} \mathrm{C}$ of allotrope transformation (coinciding with reference book data);

ii) Below this temperature range at $10^{3} / T=3,16-3,26$ (43$\left.34{ }^{\circ} \mathrm{C}\right) T_{2 \mathrm{~B}}$ of $B$ proton phase has an uneven behavior with oscillations of $T_{2 \mathrm{~B}}$ from $10 \mathrm{~ms}$ to $120 \mathrm{~ms}$. We suppose they are caused by structure-dynamical processes of temporal ordering of structure before the final crystallization at temperature $35^{\circ} \mathrm{C}\left(10^{3} / T=3,25\right)$, at which $T_{2 \mathrm{~B}}$ falls to stable value $T_{2 \mathrm{~B}}=6.3 \mathrm{~ms}$.

iii) For relaxation times $T_{2 \mathrm{~A}}$ of $A$ proton phase in the range $10^{3} / T=3,155-3,37\left(43-24^{\circ} \mathrm{C}\right)$ the decrease of $T_{2 \mathrm{~A}}$ with three clear extremes (minimums) of $T_{2 \mathrm{~A}}$ are observed. Probably they are connected with three-stage process of precrystallization ordering of $-\mathrm{CH}_{2}-\mathrm{CH}_{3}$ - groups. After that at the range $10^{3} / \mathrm{T}=3,356-3.39\left(25-22^{\circ} \mathrm{C}\right)$ we observe oscillation process with the amplitude of $T_{2 \mathrm{~A}}$ oscillations from $89 \mathrm{~ms}$ to $126 \mathrm{~ms}$. Fluctuations ends at $22^{\circ} \mathrm{C}$ by the full crystallization of the proton phase $A$ and sharp fall of $T_{2 \mathrm{~A}}$ to value $7.6 \mathrm{~ms}$ and only this temperature may be named as "rigid lattice" state of paraffin.

iiii) In the melt state of paraffine proton phase $A$ population (corresponding to the end $\mathrm{CH}_{3}$-groups) has value $P_{2 \mathrm{~A}}=65 \%$. At the temperature of the full cooling its value reach value $P_{2 \mathrm{~A}}=98 \%$, which is interpreted as that at low temperatures main contribution in relaxation comes from the end chains. Molecular fragments of $\mathrm{B}$ phase ${ }^{\ldots . . \mathrm{CH}_{2}}$ $-\mathrm{CH}_{2}-\mathrm{CH}_{2}-\ldots$

$\ldots \mathrm{CH}_{2}-\mathrm{CH}_{2}-\mathrm{CH}_{2}-\ldots$ have reached already the solid crystallized (ordered) state.

So, the conclusion can be made, that full crystallization at cooling process does not end at $T=30,4{ }^{\circ} \mathrm{C}$ (as it is indicated by literature data [5]), but goes up on till $22{ }^{\circ} \mathrm{C}$, passing through formation of temporal ordered structures, which gradually increase their degree of ordering and decrease $T_{2 \mathrm{i}}$ as it followes from eq.(7). But this ordered forms has intermediate melt states with higher relaxation times before ne order formation. This process gives oscillations of $T_{2 \mathrm{i}}$ as it is following from (7) before final crystallization.

Ordering from melt in the temperature range $10^{3} / T=$ $3,15-3,38\left(44.5-23^{\circ} \mathrm{C}\right)$ can be attributed to metastable state before ordering. But this temperature range differs for $A$ and $B$ proton phases. For proton phase $B$ it is $44.5-34^{\circ} \mathrm{C}$, for $A$ it is $25-22^{\circ} \mathrm{C}$, i.e. more mobile protons need higher degree of cooling. Range $10^{3} / T=3,16-3.39\left(43-22{ }^{\circ} \mathrm{C}\right)$, correspond to unstable intermediate state and can be named structure-dynamical phase transition (SDPT). At the end of this range, before the transition to ordered (crystal) state, expenditure of the heat is needed. Physically it need additional energy for transformation molecular fragments in the more ordered state. According to classical thermodynamics this situation can be expressed by Nernst law:

$$
\Delta \mathrm{F}-\Delta \mathrm{Q}=\mathrm{T} \Delta \mathrm{S},
$$

where $\Delta F, \Delta Q$ and $\Delta S$ are changes of free energy $F$, heat content $Q$ and entropy $S$ at temperature $T$. According the law all substances aspire to the minimum of free energy and the most stable substance has minimal $F$. For $i-\mathrm{C}_{22} \mathrm{H}_{46}$ free energy of formation is $F=12.5 \mathrm{kcal} / \mathrm{mol}$, for most stable substance graphite $F=0 \mathrm{kcal} / \mathrm{mol}$. In the case, when $F$ decreases more rapidly, then $Q$, entropy $S$ will also decrease, i.e. substance will come to more ordered form, and this will lead to decrease of $T_{2 \mathrm{i}}$. The most stable solid state will be reached only at $22{ }^{\circ} \mathrm{C}$, not $30.4{ }^{\circ} \mathrm{C}$ [5].

Solidification processes for $i-\mathrm{C}_{22} \mathrm{H}_{46}$ two proton phases end not only at different temperatures $T_{\mathrm{K}}$, but also at different times $t_{\mathrm{K}}$ (fig.2) which depend from molecular motions restrictions. For proton phase $B$ they are $T_{\mathrm{K}}=34{ }^{\circ} \mathrm{C}$ and $t_{\mathrm{K}}=$ $76 \mathrm{~min}$, for $A$ they are $T_{\mathrm{K}}=22{ }^{\circ} \mathrm{C}$ and $t_{\mathrm{K}}=156 \mathrm{~min}$. with the end of phase transition of paraffin $i-\mathrm{C}_{22} \mathrm{H}_{46}$ to crystal state.

For verification of the made conclusions alternative calorimetric method is used and were received time dependences, presented at fig.3. Considering calorimetric temperature curve of $i-\mathrm{C}_{22} \mathrm{H}_{46}$ we can see, that at 12-th minute is observed sharp break, corresponding to $T=44{ }^{\circ} \mathrm{C}$ of allotroph transition. In the time interval $t=12-180$ minutes three local extremes are observed, named exotherms Ext $1, E x t 2$ and Ext 3 . The initial of Ext $1\left(44^{\circ} \mathrm{C}\right)$ coincide with the start of pre-crystallization process in proton phase $B$, which ends at 49 -th minute at temperature $35{ }^{\circ} \mathrm{C}\left(10^{3} / \mathrm{T}=\right.$ $3,246)$. Start of Ext2 we attribute to warming of phase $B$ molecular motion for overcoming activation barrier for start of the several stages of structure-dynamical processes finishing by crystallization of phase $B$ at $34^{\circ} \mathrm{C}$ on 75 -th minute.

At the same time on 47-th minute initiated pre-crystallization of proton phase $A$. So to the exotherm Ext 2 contribute simultaneously $B$ and $A$, and this Ext 2 is the sum of at least three peaks, corresponding to 
pre-crystallization stages (three minimums of $T_{2 \mathrm{~A}}$ at fig. 1, 2). Start Ext3 at 136-th minute correspond to local warming for overcoming of the potential barrier to start orering, preceding final crystallization of $i-\mathrm{C}_{22} \mathrm{H}_{46}$ at 156-th minute, when $T_{2 \mathrm{~A}}$ sharply falls to 7,6 $-8,3 \mathrm{~ms}$., corresponding "rigid lattice",

Approximately at the same temperatures, the extremes on the tension dependence of $U_{\mathrm{TE}}(\mathrm{mV})$ (curve 4) on thermo-element are observed. It is clearly seen, that extremes, approximately coincide with the temperature peaks of exothermic processes at temperature at fig. 3 .

Time dependence of relaxation times at cooling at fig.3 support conclusions, made from fig. 1 and 2. Really, Ext 1 corresponds to decrease (protons ordering) of $T_{2 \mathrm{~B}}$. Ext2 characterize three stage pre crystallization (the minimums of $T_{2 \mathrm{~A}}$ ) of $A$ proton phase. Ext3 corresponds to final crystallization of proton phase $A$ and $i-\mathrm{C}_{22} \mathrm{H}_{46}$ in whole.

\section{Bitumen}

Bitumen, used for study contain sufficient amount of paraffins- $12.4 \%$. Experimental slopes of spin-echo amplitudes Ae in CPMG-method after amplitude detection is described by the sum of three components with relaxation times T2A, T2B and T2C, corresponding to proton phases $\mathrm{A}, \mathrm{B}$ and $\mathrm{C}$. They are can be attributed: $\mathrm{A}-$ to dispersion media of light paraffins and naphtens with high reorientation velosities of $\mathrm{CH} 3$ groups and cis-trans configuration motion of ...-CH2- $\mathrm{CH} 2-\mathrm{CH} 2 \ldots$ chains; $\mathrm{B}$ - to resins and $\mathrm{C}-$ to asphaltenes - most heavy molecular polar aromatic structures. Attribution is conventional, because protons of high mobile fragments of phases $\mathrm{B}$ and $\mathrm{C}$ can contribute in T2A of A proton phase, and on the contrary fragments of A -phase with low mobility of linear paraffins, contribute in relaxation with $\mathrm{T} 2 \mathrm{~B}$ and $\mathrm{T} 2 \mathrm{C}$. In scientific literature is used term "structure unit" (SU) [7] for description of disperse phase elements in oils. SU are phase fractal particles, which can be described on the basis of dynamical phenomenon of the fractal cluster, composed from aggregated asphaltene (or paraffin) molecules, attracted to each other and forming SU core. Solvate envelope of SU is formed mainly from resin and aromatics molecules. SU are sediment in the medium of hydrocarbons of phase A [5].

As it can be seen from temperature dependences of $\mathrm{T} 2 \mathrm{~A}$, $\mathrm{T} 2 \mathrm{~B}$ and $\mathrm{T} 2 \mathrm{C}$ in fig. 4, relaxation times reduce with temperature decrease, but the times drop is dependent from temperature. It is the indication of the activation energies EA increase with temperature fall. Use of high temperature approximation is also substantiated in the case of bitumen. In [15] was shown, that in colloid systems intermolecular contribution is much less, then intramolecular.

It was established, that with temperature fall the average $E_{\mathrm{Aav}}$, calculated from eq.(7) increase. So, for temperature range $10^{3} / T=2,6-2,78, E_{\text {Aav }}=16,7 \mathrm{~kJ} / \mathrm{mol}(4,0 \mathrm{kcal} / \mathrm{mol})$, for $10^{3} / T=2,78-2,9, E_{\text {Aav }}=20,48 \mathrm{~kJ} / \mathrm{mol}(4,9 \mathrm{kcal} / \mathrm{mol})$, for $10^{3} / T=2,9-3,4, E_{\text {Aav }}=43,9 \mathrm{~kJ} / \mathrm{mol}(10,5 \mathrm{kcal} / \mathrm{mol})$, that is can be explained by increasing restrictions of the molecular motions.

At the same time at the curves 1-3 at fig.4 observed several temperature ranges, manifesting sharp jumps of relaxation times $T_{2 \mathrm{i}}$, exceeding the experimental error several times. This changes of $T_{2 \mathrm{i}}$ with the negative slopes at high temperature side (and, consequently with negative local activation energies $E_{\mathrm{ASD}}$ ) can not be attributed neither to phase transitions of the second order, because no heat emission at this temperatures are observed (fig.6, curve 2), nor to PT of the first order, because no transition in another aggregate state takes place. We connect this peculiarities in $T_{2 \mathrm{i}}$ behavior with structure-dynamical phase transitions (SDPT), which appear as a result of temporary (dynamical) formation and following melting of the clusters of supermolecular structures on the paraffin base. In our case SDPT are accompanied by the structure ordering with decreasing of $R_{\mathrm{ij}}$ in SU and which is the cause of $T_{2 \mathrm{C}}$ and $T_{2 \mathrm{~B}}$ decrease according to eq(7) as a result of the ordering. This process is exothermic, resulting to the negative $E_{\mathrm{ACд}}$ and is the manifestation of open dissipative systems aspiration to the minimum of the free energy and entropy. More sufficient decrease of the enthalpy $H$ contribution in the $E_{\mathrm{ASD}}$ than the entropy $S$ decrease $(\Delta H<0, \Delta S<0, \mid \Delta H\}>|\Delta S|)$ gives negative $E_{\mathrm{ASD}}$ :

$$
E_{\mathrm{ASD}}=\Delta H-T \Delta S<0
$$

As it was mentioned in [16], during bitumen cooling «occur imposition of plural number of structure and phase transitions. Bitumen with high concentration of asphaltenes (up to $40 \%$ ) and paraffin-naphtens (up to 35\%) aggregative unstable and their heterogenization goes during 2 days. Concentration of disperse phase arise by the molecules, detained in dispersion media due to viscosity". Temporal dependence of $T_{2 \mathrm{~A}}$ in bitumen sample on fig. 5 demonstrate oscillations, which with coefficient $\alpha=510$ can approximately be described by equation:

$$
T_{2 \mathrm{~A}}=\cos (\alpha t)[\exp (-t / 6000)+11.4 \exp (-t / 400)
$$

Oscillating character of relaxation times at fig.5, curves 1,2 can also be explained by SDPT. Extremes of temperatures on thermogramm (fig.6, curve 2) and dependence of voltage on thermoelement (fig.6, curve 1) closely coincide with SDPT at fig.5. This is connected with absorbance of energy, necessary for transformation and ordering of the new ordered structure and is the evidence of many stage solidification process in bitumen.

It was interesting to study the influence of laser irradiation of the sample. As it is known, energy $E_{\mathrm{i}}$ of the molecule is a sum of electronic energy and energies of oscillation, rotation and translation types of motion. Irradiation lead to absorption of electromagnet energy and to transition from energy level $i$ to more high energetic level $j$ with the change on the value:

$$
\Delta E_{\mathrm{ij}}=E_{\mathrm{i}}-E_{\mathrm{j}}=h v=h c / \lambda \sim 1,2 \cdot 10^{5} / \lambda
$$

$\Delta E_{\mathrm{ij}}$ expressed in $\mathrm{kJ} / \mathrm{mol}, \lambda$ - wave length in $\mathrm{nm}, c$ - light velocity. 
Oscillating motions are the most variant, and every hydrocarbon has definite strip of absorbance in spectra. So, secondary oil aromatic residues absorb in visible range of spectra at $0,434-0,7 \mu \mathrm{m}$. In the range $1,87-2,1 \mu \mathrm{m}$ absorb waxes of petroleum and petroleum products. Laser irradiation of the samples lead to excitation of the valence oscillations of molecular fragments. If we use laser with $\lambda=$ $0,63 \mu \mathrm{m}$, we would deliver to the nuclear system energy equal

$\Delta E=1,2 \cdot 10^{5} / 633=1,895 \cdot 10^{2} \mathrm{KJ} / \mathrm{mole}=45,35 \mathrm{kcal} / \mathrm{mole}$. This is quite enough for excitation of rotarion and vibration motions. In spite of not high power of laser radiation $(0,6$ $\mathrm{W} / \mathrm{sm}^{2}$ ) it is sufficiently effective. In oil residues by exciting of molecular motion at definite wavelength (activating of definite modes), we can selectively excite definite molecular fragments ( $i$-th proton phases) motions, having corresponding relaxation times $T_{1,2 \mathrm{i}}$. Excitation lead to decreases of correlation times $\tau_{\mathrm{R}}$ of the intramolecular rotations and arise mean interproton distances $R_{\mathrm{ij}}$ due to molecular motion amplitude rise. All this factors lead (see eq.(7)) to the rise of $T_{2 \mathrm{i}}$ on a value $\Delta T_{2 \mathrm{i}}=\left(T_{2 \mathrm{~A}}{ }^{*}-\right.$ $\left.T_{2 \mathrm{~A}}\right) \cdot 100 \% / T_{2 \mathrm{~A}}$, where $T_{2 \mathrm{~A}}{ }^{*}$ is relaxation time in irradiated sample.This phenomena can be used for elimination several components of the oil and increase signal/noise level.

As it is seen from fig.5 (curve 4) irradiation sufficiently levels process of SDPT, and smoothes the oscillations of relaxation times. But it is also lead to the rise T2A increments $\triangle \mathrm{T} 2 \mathrm{~A}$ in the whole temperature range, especially at low temperatures. This effect was discussed by us in [11]. From $\Delta \mathrm{T} 2 \mathrm{~A}$ increment after laser irradiation, the concentration of paraffin in oil can be determined using equation:

$$
\text { Paraffin }=1,654+5,678 \ln \left(\Delta T_{2 \mathrm{~A}}\right)
$$

\section{Conclusions}

1. In temperature dependences of relaxation times for isoparaffine difference in behavior of $T_{2 \mathrm{i}}$ is observed at the cooling process. Relatively monotone decrease of $T_{2 \mathrm{~A}}$ and $T_{2 \mathrm{~B}}$ is changed by oscillations initially of $T_{2 \mathrm{~B}}$ and then of $T_{2 \mathrm{~A}}$, followed by the final sharp fall of $T_{2 \mathrm{i}}$ to the value of the solid state. But $T_{2 \mathrm{i}}$ changes appear at different temperatures. This is, we suppose, the indication of the independent and in different temperature range ordering of $B$ and $A$ proton phases, corresponding to configuration, and rotation motions.

2. In the melt initially proton phase $A$ population is $P_{2 \mathrm{~A}}=$ $65 \%$. But at cooling its value reaches value $P_{2 \mathrm{~A}}=98 \%$, which can be interpreted as that at lowest temperatures the main contribution in relaxation give only the most mobile end chains of $-\mathrm{CH}_{2}-\mathrm{CH}_{3}$-groups. Fragments of phase $\mathrm{B}$ are already in ordered state.

3. Solidification process for $i-\mathrm{C}_{22} \mathrm{H}_{46}$ proton phases proceed also at different time moments, depending from molecular motion restrictions. Calorimetric curve of
$i-\mathrm{C}_{22} \mathrm{H}_{46}$ initially demonstrate sharp break, corresponding to temperature of allotroph transition. Then three local extremes - exotherm Ext1, Ext2 and Ext3 are observed. Beginning of the Ext 1 coincide with the start of pre-crystallization process in proton phase $B$, start of Ext2 can be attributed to warming of phase $B$ for overcoming of activation barrier and for initialization of several stages of structure-dynamical process finishing by final ordering. At the same time begins pre-crystallization of the most mobile proton phase $A$. Start of $E x t 3$ correspond to the local $A$ phase warming, preceding final crystallization of $i-\mathrm{C}_{22} \mathrm{H}_{46}$, when $T_{2 \mathrm{~A}}$ sharply falls to values of ordered state.

4. Approximately at the same temperatures the extremes are observed on the thermo-element tension $U_{\mathrm{TE}}(\mathrm{mV})$ dependence, which approximately coincide with the temperature peaks of exothermic processes on caloric curves.

5 In bitumen with temperature decrease, activation energies $E_{\mathrm{A}}$ goes up. At the same time sharp changes of $T_{2 \mathrm{i}}$ (exceeding the experimental error in several times) are observed. This $T_{2 \mathrm{i}}$ changes can not be attributed neither to phase transitions of the second order, nor to PT of the first order.

Peculiarities in $T_{2 \mathrm{i}}$ and caloric curves behavior can be connected with structure-dynamical phase transitions (SDPT), which appear as a result of temporary (dynamical) formation and the following destruction (melting) of the supermolecular structures clusters. In our case SDPT are accompanied by the decreasing of $R_{\mathrm{ij}}$ as a result of ordering and increasing its density. Final phase transition do not end at $T=30,4{ }^{\circ} \mathrm{C}$ (as by literature data), but goes up to $22{ }^{\circ} \mathrm{C}$, passing through formation of temporal structures, which gradually increase their degree of ordering.

6. Laser irradiation of the bitumen deliver to the nuclear system energy $\Delta E$ enough for excitation of rotation and vibration motions. Excitation lead to decreases of correlation times $\tau_{\mathrm{R}}$ of the rotations and to the rise of the mean interproton distances $R_{\mathrm{ij}}$ due to molecular motion amplitude rise. Both factors lead to the rise of relaxation times $T_{2 \mathrm{i}}$ on the value $\Delta T^{*}{ }_{2 \mathrm{~A}}=\left(T_{2 \mathrm{~A}}{ }^{*}-T_{2 \mathrm{~A}}\right) \cdot 100 \% / T_{2 \mathrm{~A}}$ in the whole temperature range, especially at low temperatures. Measuring the increments $\Delta T_{2 \mathrm{~A}}$, the concentration of paraffin can be determined.

\section{REFERENCES}

[1] Dincer I. and Rosen M.A. (2003) Thermal Energy Storage: Systems and Applications, London, JohnWiley\&Sons.

[2] Farid M.M., Khudhai A.M., Razack S.A.K., Al-Hallaj S. (2005), Conversion and Management 45, 1597.

[3] Zalba B., Marin J.M., Cabeza L.F., Mehling H. (2003) Applied Thermal Engineering 23, 251.

[4] Weaver S.G., Weaver D., Weaver S.P. (2010) Power 
generation using thermal gradients main-tained by phase transitions. Patent of USA № US 7.810.330 B1.

[5] Safieva R.Z. Physic-chemistry of oil. (1998) M.: «Chimiya», p.307.

[6] Petrova L.M. Formation of residue oils composition. (2008) "FEN" publishing, National Academy of Republic of Tatarstan, Kazan, 204 p.

[7] Kashaev R.S., Faschiev N.R. (2011) Applied Magnetic Resonance, 41, i.1, 31-43.

[8] Kashaev R.S.-H., Idiatullin Z.Sh., Temnikov A.N. Device for sample thermostabilization in relaxometer NMR (2006) Patent of Russian Federation on invention \# 2319138.

[9] Hahn E.L.(1960) J.Geogr.Res. 65, 776.

[10] Meiboom S., Gill D. (1958) Review of Scientific Instruments. 29,688
[11] Kashaev R.S., Gazizov E.G. (2010) Effect of irradiation in visible and infrared spectral re-gions on nuclear magnetic relaxation parameters of protons in oil products. Journal of Applied Spectroscopy (Russian). 77 (3), 321-328.

[12] Brown R.J.S. Information available and unavailable from multiexponentional relaxation date (1989) J.Magn.Res. 82, 539-561.

[13] Vashman A.A., Pronin I.S. Nuclear magnetic relaxation and its application in chemical phys-ics. (1979), M:. "Nauka", 235 .

[14] Callaghan J.E., Sullivan S.A. (1986), Rev. Sci. Instr. 57, \#10, 2593-2598.

[15] Frolov V.V. Models of molecular motion in theory of proton relaxation in liquids / In Nuclear magnetic resonance. (1969) St.Pb: Ed. St.Pb. University. III. 15-29.

[16] Pechenyi B.G. Bitumen and bitumen compositions. (1990) M:,"Chimia", 256 